\title{
THE RELATIONSHIP BETWEEN TWO APPARENTLY DIFFERENT ENTEROTOXINS PRODUCED BY ENTEROPATHOGENIC STRAINS OF ESCHERICHIA COLI OF PORCINE ORIGIN
}

\author{
H. Williams Smith and C. L. Gyles* \\ Animal Health Trust, Stock, Essex \\ Plates XXXIV AND XXXV
}

BY means of tests in ligated segments of pig intestine, Smith and Halls (1967b) demonstrated an enterotoxin in the bacteria-free fluids of soft agar cultures of all the strains of Escherichia coli they examined that had been incriminated in outbreaks of neonatal and post-weaning diarrhoea in pigs.

This enterotoxin retained most of its activity after $30 \mathrm{~min}$. at $100^{\circ} \mathrm{C}$, but was inactivated after $30 \mathrm{~min}$. at $121^{\circ} \mathrm{C}$. It will therefore be referred to as the heat-stable enterotoxin or ST. Although ST could occasionally be detected intracellularly in bacteria grown on soft agar cultures, it was mainly extracellular. In some strains of $E$. coli its production was controlled by a transmissible plasmid designated Ent (Smith and Halls, 1968). Later work (Smith, unpublished) has revealed that the ability of ST to dilate ligated segments of pig intestine is not neutralised by antiserum. Kohler (1968) demonstrated an enterotoxin probably identical with ST that produced diarrhoea in young piglets after intragastric administration.

Gyles and Barnum (1969) used the pig ligated intestine test to demonstrate what appeared to be an additional enterotoxin in cultures of some pig-enteropathogenic strains of $E$. coli. The additional enterotoxin differed sharply from ST in that it could be inactivated by antiserum and by heating to $60^{\circ} \mathrm{C}$ for $30 \mathrm{~min}$; accordingly, it is here referred to as the heatlabile enterotoxin or LT. Although LT could sometimes be detected occurring extracellularly in cultures in liquid media, it was most consistently demonstrated in lysates of bacterial cells.

The present paper is concerned with the distribution of ST and LT among different strains of $E$. coli enteropathogenic for pigs and with their relationship to each other. The study of their relationship was greatly aided by the discovery that production of LT as well as ST was controlled by a transmissible plasmid (Ent); this led us to believe that LT and ST are essentially two forms of the same enterotoxin. The finding also enabled us to experiment with strains of $E$. coli that were identical except for the fact that they had had different Ent plasmids transmitted to them. Any differing results obtained with these strains could be attributed to the activity of the Ent plasmids.

\section{MATERIALS AND METHODS}

Strains of Escherichia coli. All strains of $E$. coli. were maintained on Dorset egg medium at $5^{\circ} \mathrm{C}$. Those from pigs were given the prefix $P$, those from human beings, $H$, and those

Received 5 Aug. 1969; accepted 5 Dec. 1969.

* Research Fellow, Medical Research Council of Canada.

3. MED. MICROBIOL.-VOL. 3 (1970) 
from fowls, F. For ligated intestine tests they were grown in nutrient broth (Oxoid, no. 2) for $18 \mathrm{hr}$ at $37^{\circ} \mathrm{C}$ and then injected into the ligated segments in $1-\mathrm{ml}$ amounts.

Preparation of heat-stable enterotoxin $(S T)$. This was performed by the soft agar method of Smith and Halls (1967b), the culture fluids being held at $65^{\circ} \mathrm{C}$ for $15 \mathrm{~min}$. after they had been separated from the bacteria by centrifugation. Culture fluids used in ligated intestine tests were treated with neomycin and polymyxin, $100 \mu \mathrm{g}$ of each per ml, to prevent the growth of enterotoxigenic bacteria, which are very occasionally present in the intestine. The dose of culture fluid used in these tests was $15 \mathrm{ml}$.

Preparation of heat-labile enterotoxin $(L T)$. This was performed by a modification of the method of Gyles and Barnum (1969), the bacterial growth from each Roux flask of tryptose agar (Oxoid) containing 0.2 per cent. of glucose being washed off with $20 \mathrm{ml}$ of distilled water and disintegrated ultrasonically. The resulting lysate was centrifuged for $30 \mathrm{~min}$. at 3000 r.p.m. in the angle-head of an M.S.E. Major centrifuge to remove bacterial debris and filtered through a membrane filter with an average pore diameter of $450 \mathrm{~nm}$. Antibiotics were added in the same manner as they were added to ST preparations. The dose of LT employed in ligated intestinal tests, unless otherwise stated, was $6 \mathrm{ml}$. A lysate of every strain judged by this method to be a producer of LT was also tested after being held at $65^{\circ} \mathrm{C}$ for $15 \mathrm{~min}$; these tests were always negative, indicating that detectable amounts of ST were not produced when strains were grown and treated in this way.

Ligated intestine preparations. The technique employed has been described fully elsewhere (Smith and Halls, 1967a); it did not differ essentially from that of Gyles and Barnum. Briefly, weaned 8-12-week-old pigs that had been starved for $24 \mathrm{hr}$ were anaesthetised and the small intestine of each, beginning $1 \mathrm{~m}$ from the pylorus and ending $3 \mathrm{~m}$ from the caecum, was divided into segments $10-12 \mathrm{~cm}$ long with string ligatures. The test materials were injected into alternate segments and the intermediate segments were left as untreated controls. It was possible to perform at least 50 tests in each pig. The abdomen was then closed and each of the pigs was allowed to recover from anaesthesia. They were killed $24 \mathrm{hr}$ later and the presence or absence of dilatation of the segments and the volume and character of the contained fluid were recorded. Since the segments were of approximately equal length, the volume of fluid recovered served as a measure of the severity of the reaction. In assessing this, however, the region of the intestine in which a test was made had to be taken into consideration, because the anterior portion is more susceptible to dilatation than the posterior portion, susceptibility decreasing gradually antero-posteriorly. For this reason, materials to be compared were always tested in segments close to each other.

Consistent results are obtained when strains of $E$. coli are tested by the procedure outlined above and positive segments are easily differentiated from negative ones. Positive segments in the anterior test region contain $20-80 \mathrm{ml}$ of exudate, and in the posterior test region seldom less than $10 \mathrm{ml}$; in contrast, negative segments contain $0.2-0.5 \mathrm{ml}$ of red amorphous semisolid material. The anterior $3 \mathrm{~m}$ of the test region is always used for testing the enterotoxigenicity of cell-free fluids, the less reactive posterior region being unreliable for this purpose. Cell-free fluids from non-enterotoxigenic strains are usually completely absorbed from the segments into which they have been injected. Sometimes, however, a few $\mathrm{ml}$ of thick mucoid fluid remain. On the other hand, segments into which cell-free fluids containing either ST or LT have been injected are usually markedly dilated and often contain as much as $120 \mathrm{ml}$ of exudate; they rarely contain less than $20 \mathrm{ml}$ of exudate. Occasionally, however, a pig has to be rejected as unsuitable for studies of ST and LT because of poor reactivity of the small intestine; tests with live cultures in these pigs are satisfactory, but the amount of fluid that accumulates in the segments is definitely less than usual. The reason for this poor reactivity is not known, but it was largely overcome by using thriving pigs from one source.

Estimation of the numbers of viable E. coli in ligated segments. This was performed by a modification of the method of Miles and Misra (Miles, Misra and Irwin, 1938), the whole segment and its contents being ground together in a pestle and mortar with sterile sand. The culture medium used was blood agar.

Transfer of ability to produce enterotoxin. This was performed by the method of Smith and Halls (1968). Essentially, this involved the growing together in nutrient broth of an 
enterotoxigenic streptomycin-sensitive donor strain of $E$. coli and a streptomycin-resistant mutant of a non-enterotoxigenic strain, the recipient strain. The mixed culture was then passed twice in nutrient broth containing streptomycin, $50 \mu \mathrm{g}$ per ml, and finally through plain nutrient broth. After confirming that this final culture contained organisms of the recipient strain only, it was submitted in the usual way to the ligated intestine test in a pig. If dilatation resulted, broth cultures seeded from individual colonies obtained from the final culture of the recipient strain were then examined to determine those strains that produced dilatation and those that did not. Those that did were designated by the number of the recipient strain followed by the number of the donor strain, in brackets, and the symbol Ent ${ }^{+}$; those that did not were designated in the same way except that they were given the symbol Ent ${ }^{-}$. In a similar manner, strains to which the plasmid controlling K88 antigen production was transmitted (Stirm, Ørskov and Ørskov, 1966) were given the symbol $88^{+}$; those that had lost it were designated $88^{-}$.

Preparation of antisera. Pigs approximately $12 \mathrm{wk}$ old were given live 18 -hr broth cultures of strains of $E$. coli intravenously on 3 consecutive days in each week for 4 wk. The dose was gradually increased from an initial volume of $0.5 \mathrm{ml}$ to a final dose of $5 \mathrm{ml}$. One week after the last dose was given, the pigs were killed and their blood was collected. When ST preparations were used instead of live cultures, the vaccination procedure adopted was essentially the same.

In neutralisation tests, varying doses $(2-7 \mathrm{ml})$ of the antisera were mixed with 6-ml volumes of LT preparations, $15-\mathrm{ml}$ volumes of ST preparations or $0 \cdot 25-\mathrm{ml}$ volumes of 18-hr nutrient broth cultures of living organisms, $\frac{1}{2}-1 \mathrm{hr}$ before they were injected into ligated segments. When tested against living organisms the dose of antiserum was $2 \mathrm{ml}$; in tests against LT and ST preparations the dose varied as noted in the text.

The administration of enterotoxin to piglets. Piglets, approximately $24 \mathrm{hr}$ old, were removed from their mother in turn and given, by means of a stomach tube attached to a syringe, the LT or ST preparation under test. Administration occupied only a few minutes, after which each piglet was returned to its mother. All the materials tested in piglets were prepared from recipient organisms that had been grown in mixed culture with donor strains and had or had not received Ent, as judged by ligated intestine tests. This made it possible to compare identically prepared materials that differed from each other by virtue of the fact that one organism contained the Ent plasmid and the other did not. One group of piglets in each litter was given material from the Ent ${ }^{+}$strain and another group of the same size was given material from the corresponding Ent-strain; a third group was kept as untreated controls. The piglets were observed frequently for evidence of diarrhoea. The faeces of some of those that developed diarrhoea were examined for the presence of enteropathogenic $E$. coli; none yielded this organism. Because the diarrhoea in some of the piglets in the earlier experiments was so severe as to cause death, all the piglets that subsequently developed diarrhoea were given kaolin orally and normal saline subcutaneously.

\section{RESULTS}

\section{The heat-labile (LT) and heat-stable (ST) enterotoxin \\ Production by different strains of Escherichia coli}

The results of examining 60 wild strains of $E$. coli for ability to produce heat-labile (LT) and heat-stable (ST) enterotoxin are illustrated in table I. Of the 40 strains grouped together according to antigenic structure, 37 had been isolated from epidemiologically unrelated outbreaks of neonatal or postweaning diarrhoea in pigs under conditions that strongly suggested that these organisms were playing a pathogenic role; all 15 antigenic types are ones generally considered to be pathogenic for pigs. The remaining three were derived from three of the 37 strains. Two of the three, $08: \mathrm{K}_{87,88 \mathrm{ab}^{-}}$and 
O141:K85ab,88ab-, were variants of $\mathrm{K} 88+$ strains that had lost the ability to produce the $\mathrm{K} 88$ antigen. The third strain, $\mathrm{O} 141: \mathrm{K} 85 \mathrm{ac}, 88 \mathrm{ab}^{+}$, was an O141:K85ac strain, into which Dr Ida Ørskov had introduced the plasmid responsible for K88ab production. The two strains of antigenic type O139:K82 that were examined were the only two of 24 strains of this type found by Smith and Halls (1968) to produce enterotoxin, production of enterotoxin in both strains being plasmid-controlled; O139:K82 strains are usually implicated

TABLE I

The production of heat-labile $(L T)$ and heat-stable $(S T)$ enterotoxin by different strains of Escherichia coli

\begin{tabular}{|c|c|c|c|c|}
\hline \multirow{2}{*}{ Antigenic formula } & \multirow{2}{*}{$\begin{array}{c}\text { Number of } \\
\text { strains examined }\end{array}$} & \multirow{2}{*}{$\begin{array}{l}\text { Ligated intestine } \\
\text { test result with } \\
\text { live cultures }\end{array}$} & \multicolumn{2}{|c|}{$\begin{array}{l}\text { Type of enterotoxin } \\
\text { produced }\end{array}$} \\
\hline & & & $\mathbf{L T}$ & ST \\
\hline 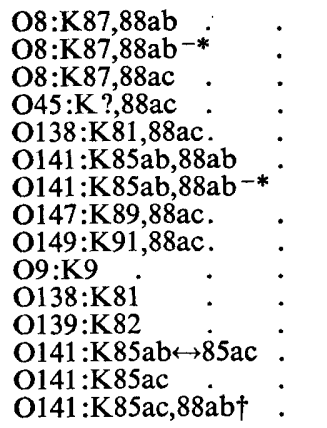 & $\begin{array}{l}3 \\
1 \\
3 \\
3 \\
3 \\
3 \\
1 \\
3 \\
5 \\
3 \\
3 \\
2 \\
3 \\
3 \\
1\end{array}$ & $\begin{array}{l}+ \\
+ \\
+ \\
+ \\
+ \\
+ \\
+ \\
+ \\
+ \\
+ \\
+ \\
+ \\
+ \\
+ \\
+\end{array}$ & $\begin{array}{l}+ \\
+ \\
+ \\
+ \\
+ \\
+ \\
+ \\
+ \\
+ \\
= \\
= \\
= \\
=\end{array}$ & $\begin{array}{l}+ \\
+ \\
+ \\
+ \\
+ \\
+ \\
+ \\
+ \\
+ \\
+ \\
+ \\
+ \\
+ \\
+ \\
+\end{array}$ \\
\hline Various or untypable & 20 & - & - & - \\
\hline
\end{tabular}

* Strains that did not possess the K88ab antigen were derived from strains that did.

$\dagger$ This was an 0141:K85ac strain to which the K88ab plasmid had been transmitted.

in oedema disease and not in diarrhoea. All 40 strains dilated ligated pig intestine when tested as live cultures. The remaining 20 strains classified in table I as various or untypable were not known to have any association with porcine disease; none of them dilated ligated pig intestine.

Table I shows that all 40 strains classed as enteropathogenic produced ST, but only those strains that naturally possessed, or had possessed, the K88 antigen produced LT also; the $0141:$ K85ac strain into which the K88 plasmid had been transmitted produced only ST. This differentiation into "LT-ST producers" and "ST only" producers was clear-cut. LT-type preparations were made on several occasions from many of the pathogenic strains that had never been shown to possess K88 antigen; they consistently failed to dilate ligated pig intestine. A slight dilatation was sometimes produced when the test dose was increased from the customary $6 \mathrm{ml}$ to $16 \mathrm{ml}$; comparative tests 
with identical preparations that had been held at $65^{\circ} \mathrm{C}$ for $15 \mathrm{~min}$. indicated that the dilatation was caused by the presence of small amounts of ST in the preparation.

In general, there was no obvious difference in the amount of exudate that accumulated in ligated segments into which ST prepared from strains that produced this enterotoxin only and from those that also produced LT had been injected. ST-type preparations of strains that appeared to produce only ST provoked the same degree of reaction in ligated intestine whether or not they had been submitted to the customary heat treatment. Neither was it possible to detect LT in the unheated preparation by submitting it to dialysis, a procedure that causes some loss of ST (Kohler) but not of LT (Gyles and Barnum). Dialysis produced a definite reduction in enterotoxin content, but subsequent heat treatment had no effect on dilating ability. A definite additive effect was demonstrable when mixtures of LT and ST preparations of strains that produced both enterotoxins were injected into ligated segments. For example, the volumes of fluid that accumulated in two ligated segments separately treated with LT and ST preparations of one such strain were 90 and $130 \mathrm{ml}$ respectively. In a segment into which a mixture comprising one dose of each was injected, the volume that accumulated was $188 \mathrm{ml}$. In a similar experiment with a different strain, the corresponding volumes of exudate were 48,108 and $140 \mathrm{ml}$. When this kind of experiment was performed in relatively unreactive regions of the small intestine, negative reactions were sometimes obtained when the LT and ST preparations were tested singly and positive ones when they were tested together. In one such experiment, the volumes of exudate provoked by the LT preparation, the ST preparation and the mixture of both were respectively 5,0 and $62 \mathrm{ml}$. In two similar experiments the corresponding volumes were 0,15 and 52, and 8, 12 and $76 \mathrm{ml}$.

No difference was detected macroscopically between the dilatation produced by LT and by ST. The anterior small intestine was the most susceptible to the action of both enterotoxins, susceptibility to each decreasing to the same extent from anterior to posterior. No obvious difference, quantitative or qualitative, was noted in the exudate provoked by the two enterotoxins or in the appearance of the wall of the intestinal segments into which they had been injected.

\section{The transmission of the ability to produce LT and ST from porcine enteropathogenic strains of $E$. coli}

The results of transmitting the ability to produce enterotoxin (Ent) from each of 12 donor strains to one or more of ten recipient strains of $E$. coli are summarised in table II; some of the results are also illustrated in fig. 1. Five of the donor strains, P3, P16, P18, P103 and P255 had previously been shown to transmit Ent (Smith and Halls, 1968); the possession of this property by the remaining seven strains was discovered during the course of the present investigation. In both investigations, Ent transmission was not detected from 60 enteropathogenic porcine strains, over half of which possessed the K88 antigen; it was possible to transmit other characters such as antibiotic resistance 
( $\mathrm{R}$ factors), colicine production (Col) and $\alpha$-haemolysin production (Hly) from many of them.

Apart from demonstrating that production of LT as well as ST is transmissible, the results show that each Ent ${ }^{+}$recipient strain examined produced exactly the same type or types of enterotoxin as that produced by the strain from which it had received Ent. None of the 29 strains that had received Ent

TABLE II

The transmission of the ability to produce LT and ST from enteropathogenic strains of E. coli

\begin{tabular}{|c|c|c|c|c|c|}
\hline $\begin{array}{l}\text { Donor } \\
\text { strain }\end{array}$ & $\begin{array}{l}\text { Antigenic } \\
\text { formula }\end{array}$ & $\begin{array}{l}\text { Enterotoxins } \\
\text { produced }\end{array}$ & $\begin{array}{l}\text { Known transmissible } \\
\text { characters possessed } \\
\text { other than Ent* }\end{array}$ & $\begin{array}{l}\text { Recipient strains of } \\
\text { E. coli to which entero- } \\
\text { toxin production (Ent) } \\
\text { was transmitted } \dagger\end{array}$ & $\begin{array}{c}\text { Enterotoxins } \\
\text { produced by } \\
\text { Ent }{ }^{+} \text {recipient } \\
\text { strains }\end{array}$ \\
\hline P3 & 0139:K82 & ST & None & $\mathrm{K} 12 \mathrm{~F}-, \mathrm{P} 10, \mathrm{P} 20, \mathrm{P} 30$, & ST \\
\hline $\begin{array}{l}\text { P16 } \\
\text { P122 } \\
\text { P212 } \\
\text { P215 } \\
\text { P255 } \\
\text { P18 } \\
\text { P103 }\end{array}$ & $\begin{array}{l}\text { O9:K9 } \\
\text { O141:K85ac } \\
\text { O138:K81 } \\
\text { O138:K81 } \\
\text { O139:K82 } \\
\text { O8:K87,88ab } \\
\text { O8:K87,88ab }\end{array}$ & $\begin{array}{c}\text { ST } \\
\text { ST } \\
\text { ST } \\
\text { ST } \\
\text { ST } \\
\text { LT and ST } \\
\text { LT and ST }\end{array}$ & $\begin{array}{l}\text { None } \\
\text { Hly } \\
\text { Hly } \\
\text { Hly } \\
\text { Hly, Col } \\
\text { R } \\
\text { Hly }\end{array}$ & $\begin{array}{l}\text { P104, F11, H1 } \\
\text { P104 } \\
\text { P104 } \\
\text { F11 } \\
\text { P104 } \\
\text { P104 } \\
\text { P4(3) } \ddagger, \text { P66, P104(2), } \\
\text { F11(3) }\end{array}$ & $\begin{array}{c}\text { ST } \\
\text { ST } \\
\text { ST } \\
\text { ST } \\
\text { ST } \\
\text { LT and ST } \\
\text { LT and ST }\end{array}$ \\
\hline $\begin{array}{l}\text { P155 } \\
\text { P233 } \\
\text { P237 } \\
\text { P307,88ab- }\end{array}$ & $\begin{array}{l}\text { O149:K91,88ac } \\
\text { O8:K87,88ac } \\
\text { O8:K87,88ac } \\
\text { O8:K87 }\end{array}$ & $\begin{array}{l}\text { LT and ST } \\
\text { LT and ST } \\
\text { LT and ST } \\
\text { LT and ST }\end{array}$ & $\begin{array}{l}\text { Hly, Col, R } \\
\text { Hly, Col, R, } 88 \\
\text { Hly, } 88 \\
\text { Hly }\end{array}$ & $\begin{array}{l}\text { P104(2), F11 } \\
\text { P104, F11(4) } \\
\text { F11(2) } \\
\text { K12F-(2), P4(3), P23, } \\
\text { F11(3) }\end{array}$ & $\begin{array}{l}\text { LT and ST } \\
\text { LT and ST } \\
\text { LT and ST } \\
\text { LT and ST }\end{array}$ \\
\hline
\end{tabular}

$* \mathrm{Hly}=$ Haemolysin production, $\mathrm{Col}=$ colicine production, $88=\mathrm{K} 88$ antigen production, $\mathbf{R}=$ antibiotic resistance.

$\dagger$ The figures in brackets are the number of Ent ${ }^{+}$strains tested when there were more than one.

$\ddagger$ P4, P10, P20, P30 and P66 were unrelated strains of $E$. coli isolated from healthy pigs; they did not belong to any of the internationally recognised serotypes. P23, P104, F11 and $\mathrm{H} 1$ possessed the antigenic formulae $\mathrm{O} 141: \mathrm{K} 85 \mathrm{ab} \leftrightarrow \mathrm{ac}, \mathrm{O} 139: \mathrm{K} 82, \mathrm{O} 18: \mathrm{K}$ ? and $\mathrm{O} 26: \mathrm{K} 60: \mathrm{H}^{-}$respectively.

from donor strains that produced both LT and ST was found to produce only one or other of these enterotoxins; they all produced both. Some of these $29 \mathrm{Ent}^{+}$recipient strains were specially selected because they differed from each other in having received different plasmids, such as Hly, Col and R, or different combinations of these plasmids, from the same donor strains; it was thought that this might have aided the search for recipient strains that produced only LT or only ST.

Despite the close correlation between ability to produce LT and possession of the $\mathrm{K} 88$ antigen, none of the strains that had received the ability to produce LT had also acquired the K88 plasmid.

The dilating ability of strains of E. coli that produced both LT and ST or ST only

The results of transmitting Ent from eight different enteropathogenic strains of E. coli to strain P104 and then testing live cultures of the eight Ent + 
ENTEROTOXINS OF ESCHERICHIA COLI

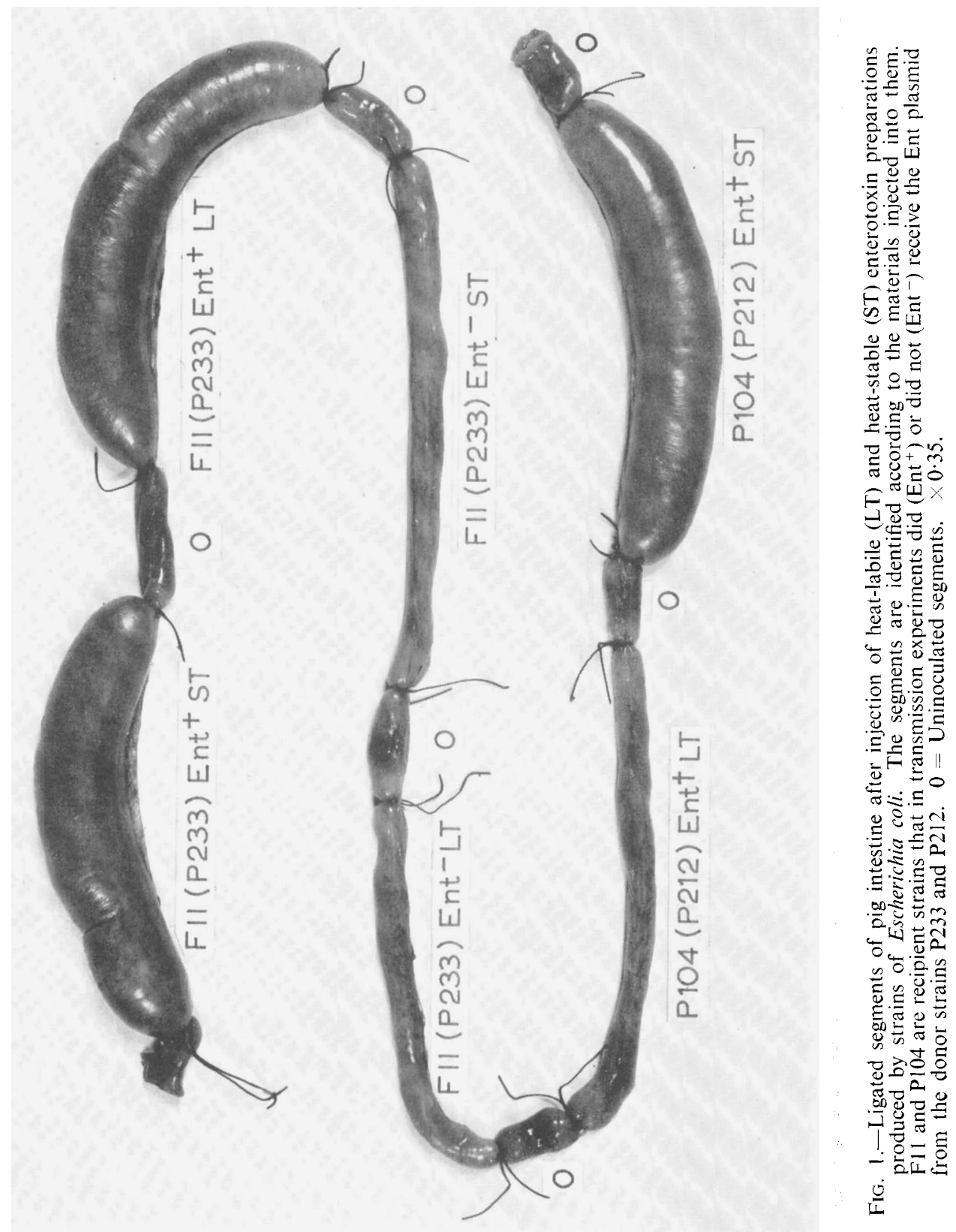


ENTEROTOXINS OF ESCHERICHIA COLI

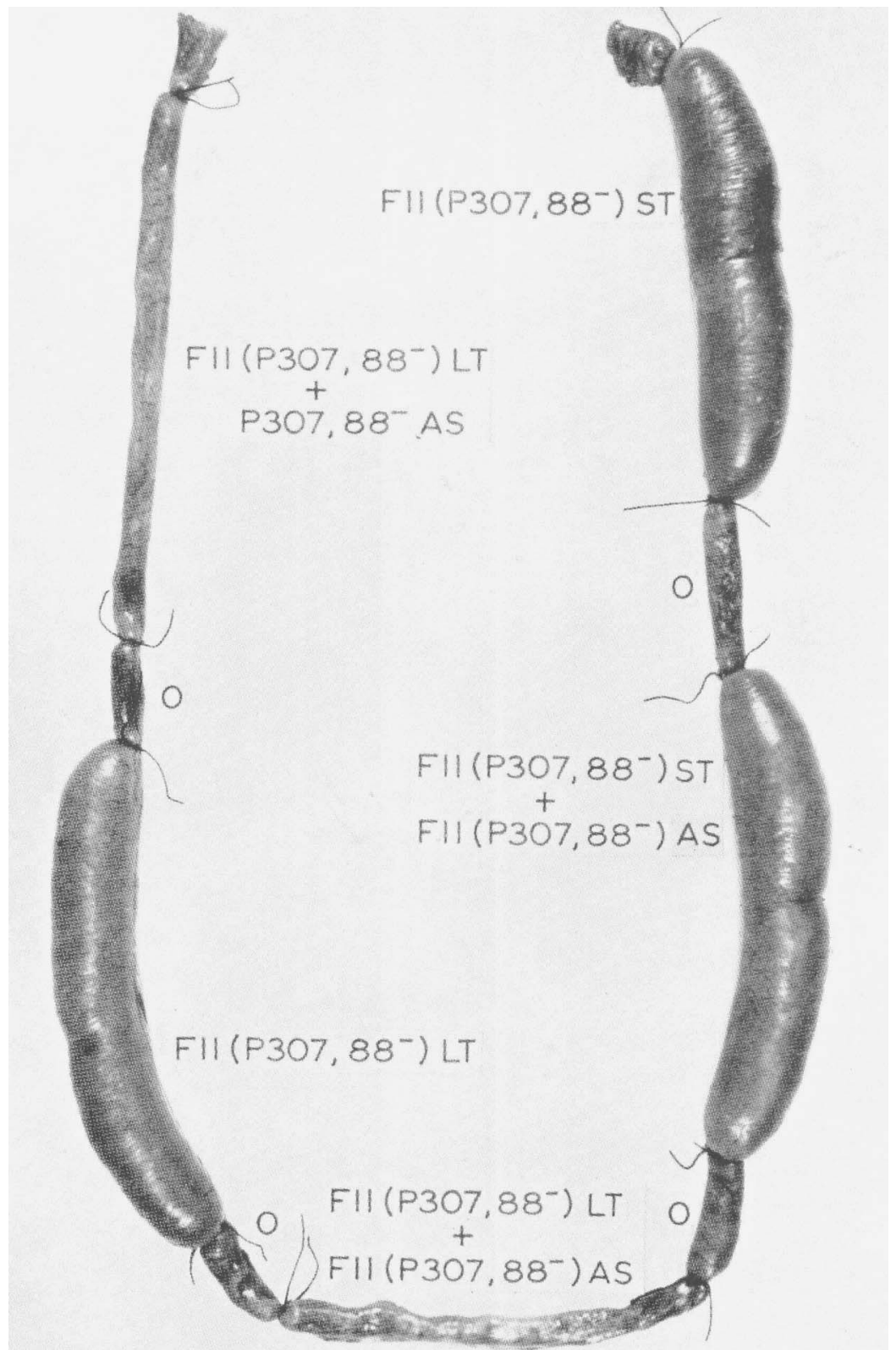

FIG. 2.--Ligated segments of pig intestine after injection with mixtures of LT or ST enterotoxin preparations and antiserum (AS) against live Escherichia coli organisms. F11(P307,88-) is a strain of F11 that has received Ent from the donor strain P307,88-. $0 \equiv$ Uninoculated segments. $\times 0.35$. 
recipient strains in ligated intestine segments of each of nine pigs is shown in table III; four strains were producers of LT and ST, and four produced ST only. The eight strains were tested in consecutive ligated intestine segments in each pig, but the relative position of the segments receiving each strain varied from pig to pig. The apparent difference in reactivity between some of the pigs was principally attributable to this variation of the location of tests in each pig. The best dilating strain was clearly P104(P155)Ent ${ }^{+}$, a producer of LT and ST. As a group, there was no obvious difference in dilating ability between the other three LT-ST producers and the four producers of ST only.

TABLE III

The gut-dilating effect of live organisms of Escherichia coli strain P104 into which Ent had been introduced from different enteropathogenic strains of E. coli*

\begin{tabular}{|c|c|c|c|c|c|c|c|c|c|c|c|}
\hline \multirow{2}{*}{ Strain tested $\dagger$} & \multirow{2}{*}{$\begin{array}{l}\text { Type of enterotoxin } \\
\text { produced in vitro }\end{array}$} & \multicolumn{9}{|c|}{$\begin{array}{l}\text { Volume of exudate }(\mathrm{ml}) \text { in ligated } \\
\text { intestinal segment of pig no. }\end{array}$} & \multirow{2}{*}{ Median: } \\
\hline & & 1 & 2 & 3 & 4 & 5 & 6 & 7 & 8 & 9 & \\
\hline $\begin{array}{l}\text { P104(P3)Ent }{ }^{+} \\
\text {P104(P1 22)Ent } \\
\text { P104(P212)Ent } \\
\text { P104(P16)Ent } \\
\text { P104(P1 8)Ent } \\
\text { P1 } \\
\text { P104(P103)Ent } \\
\text { P104(P233)Ent } \\
\text { P104(P1 55)Ent }\end{array}$ & $\begin{array}{c}\text { ST } \\
\text { ST } \\
\text { ST } \\
\text { ST } \\
\text { ST and LT } \\
\text { ST and LT } \\
\text { ST and LT } \\
\text { ST and LT }\end{array}$ & $\begin{array}{r}25 \\
16 \\
21 \\
30 \\
7 \\
20 \\
45 \\
54\end{array}$ & $\begin{array}{r}15 \\
8 \\
10 \\
16 \\
4 \\
15 \\
19 \\
35\end{array}$ & $\begin{array}{r}8 \\
5 \\
9 \\
5 \\
4 \\
7 \\
14 \\
26\end{array}$ & $\begin{array}{l}13 \\
12 \\
19 \\
18 \\
12 \\
12 \\
11 \\
38\end{array}$ & $\begin{array}{r}7 \\
12 \\
15 \\
12 \\
8 \\
12 \\
12 \\
12 \\
42\end{array}$ & $\begin{array}{r}5 \\
8 \\
10 \\
13 \\
12 \\
10 \\
12 \\
30\end{array}$ & $\begin{array}{r}5 \\
8 \\
9 \\
12 \\
8 \\
6 \\
13 \\
28\end{array}$ & $\begin{array}{r}4 \\
4 \\
10 \\
8 \\
9 \\
9 \\
10 \\
25\end{array}$ & $\begin{array}{r}13 \\
15 \\
15 \\
15 \\
10 \\
8 \\
16 \\
32\end{array}$ & $\begin{array}{r}8 \\
8 \\
10 \\
13 \\
8 \\
10 \\
13 \\
32\end{array}$ \\
\hline
\end{tabular}

* The dose injected into each segment was $1 \mathrm{ml}$ of a broth culture.

$\dagger$ The numbers in brackets are those of the Ent ${ }^{+}$donor strains. The antigenic formula of P3 was O139:K82; of P122 was O141:K85ac; of P16 was O9:K9; of P18 and P103 was O8:K87,88ab; of $\mathrm{P} 233$ was O8:K87,88ac; and of P155 was O149:K91,88ac.

$\ddagger$ Median value of results in the nine pigs.

\section{The enterotoxin-neutralising activity of antisera}

Unless otherwise stated, the volumes of antisera used in these studies were $2 \mathrm{ml}$. ST and LT preparations were used in doses of $15 \mathrm{ml}$ and $6 \mathrm{ml}$ respectively (see Methods). Some of the results are illustrated in fig. 2.

Tests with LT and antisera prepared against organisms that produced LT and ST

The strain of $E$. coli principally employed in these particular experiments was F11(P307,88 -)Ent +, the F11 strain into which the LT-ST-producing Ent + plasmid of strain P307,88 - had been transmitted. P307,88- originally possessed the antigenic structure O8:K87,88ab, but had lost its K88 plasmid. One segment in each of six pairs of ligated segments received an LT preparation of this strain together with antiserum against its living organisms; the other segments received injections of a similar LT preparation with antiserum against 
living F11 organisms. The volumes (ml) of fluid that accumulated in each pair of segments, that in the segment containing F11(P307,88-)Ent ${ }^{+}$antiserum being given first, were 25 and 90, 4 and 85,0 and 45, 0 and 40, 0 and 40, and 0 and 30. The volume of fluid that accumulated in a segment treated with the LT preparation and prevaccinal serum, from the pig used to prepare the F11(P307,88-)Ent ${ }^{+}$antiserum, was $95 \mathrm{ml}$.

The dilating effect of LT preparations from strain F11(P307,88-)Ent ${ }^{+}$ was also neutralised by antisera prepared against living organisms of P307,88and of three wild enteropathogenic strains, all of different antigenic structure and producers of LT.

The antiserum prepared against F11(P307,88-)Ent ${ }^{+}$, apart from neutralising LT preparations from strain F11(P307,88-)Ent + itself, also neutralised LT preparations from $\mathrm{P} 307,88^{-}$and from strains of $E$. coli $\mathrm{P} 104$ into which Ent had been transmitted from three different donors.

\section{Tests with $L T$ and antisera prepared against organisms that produced ST only}

Antisera prepared against live organisms of $\mathrm{F} 11(\mathrm{P} 215)$ Ent ${ }^{+}$, a strain that had been found to produce ST but not LT, did not neutralise LT preparations of F11(P307,88-)Ent + when the usual 2-ml dose of antiserum was used. When the dose of antiserum was increased to $6 \mathrm{ml}$, neutralisation was demonstrated. For example, when one segment of each of five pairs of ligated segments received this LT preparation plus $6 \mathrm{ml}$ of F11(P215)Ent ${ }^{+}$antiserum and the others received injections of a similar preparation plus $6 \mathrm{ml}$ of $\mathrm{F} 11$ antiserum, the volumes $(\mathrm{ml})$ of fluid that accumulated in each pair of segments, that for the segment injected with the F11(P215)Ent ${ }^{+}$antiserum being given first, were 10 and 110,0 and 110,0 and 90,0 and 90 , and 0 and 60 . The dilating effect of the LT of F11(P307,88-)Ent ${ }^{+}$was also neutralised by $6 \mathrm{ml}$ of antiserum against three wild strains that had been found to produce ST but not LT. No fluid at all accumulated in a segment in which antiserum against one of these strains, $\mathrm{P} 16$, with the antigenic formula $\mathrm{O} 9: \mathrm{K} 9$, was tested. In contrast, $180 \mathrm{ml}$ of exudate accumulated in an adjacent segment in which the corresponding prevaccinal serum was tested. The volume of exudate in a segment in which normal saline was used instead of serum was $195 \mathrm{ml}$.

\section{Tests with LT and antisera against ST}

Antisera prepared against ST preparations, i.e., heated bacteria-free soft agar culture fluids, did not neutralise LT preparations from strain F11(P307,88-)Ent ${ }^{+}$. Six wild enteropathogenic strains of different antigenic structure were used for producing the antisera; three produced LT as well as ST. No significant difference was noted between the amount of fluid that accumulated in segments treated with the LT of F11(P307,88-)Ent ${ }^{+}$plus $6 \mathrm{ml}$ of one or other of the six antisera and the amount that accumulated in the corresponding segments given the same LT plus $6 \mathrm{ml}$ of the prevaccinal sera from the six pigs used to prepare these antisera. 
Tests with ST and antisera prepared against organisms that produced LT and ST

Antisera prepared against living organisms of three strains of $E$. coli that produced both LT and ST did not neutralise ST. For example, when one segment of each of eight pairs of ligated segments received a mixture of ST of P307,88 - plus $7 \mathrm{ml}$ of antiserum prepared against living organisms of this strain and the other segments received injections of the same ST plus $7 \mathrm{ml}$ of normal saline, the volumes $(\mathrm{ml})$ of fluid that accumulated in each pair of segments, that for the segment injected with the antiserum being given first, were 85 and 140, 100 and 110, 90 and 100, 90 and 90, 75 and 110,65 and 75, 55 and 68, and 30 and 40 . Although most of the segments given ST with antiserum contained rather less fluid than the corresponding segments that received ST with saline, this was not considered to be due to specific antibody neutralisation. The other two antisera were each tested on one occasion only, their neutralisng effects being compared with those of prevaccinal serum and normal saline; no dilatation-inhibition occurred.

\section{Tests with ST and antisera prepared against organisms that produced ST only}

An antiserum prepared against living organisms of strain F11(P215)Ent +, the strain that had been found to produce ST but not LT, did not neutralise ST preparations of this strain. One of each of six pairs of ligated segments received an injection of this preparation plus $7 \mathrm{ml}$ of F11(P215)Ent ${ }^{+}$antiserum and the other a similar preparation plus $7 \mathrm{ml}$ of $\mathrm{F} 11$ antiserum; the volumes (ml) of fluid that accumulated in each pair of segments, that for the segment that received F11(P215)Ent + antiserum being given first, were 105 and 90 , 90 and 72, 72 and 55, 44 and 38, 38 and 34, and 20 and 20. No neutralisation of the dilating effect of ST preparations of F11(P215)Ent + was obtained with antisera prepared against living organisms of another two strains of $E$. coli that produced ST only.

\section{Tests with ST and antisera prepared against $S T$}

The antisera prepared against ST preparations of six different enteropathogenic $E$. coli that were used in the LT neutralisation studies were also used, in 7-ml amounts, in these experiments. Each one was tested against its homologous ST specimen, prevaccinal serum being used as a control. Each prevaccinal serum and the postvaccinal anti-ST serum were tested for neutralising potency in adjacent ligated segments. The volume $(\mathrm{ml})$ of fluid that accumulated in these pairs of segments, that for the prevaccinal serum being given first, was 100 and 95,80 and 60,45 and 65,35 and 30,25 and 30 , and 25 and 25 . It is clear that no specific neutralisation was demonstrated.

The effect of antisera on the dilating ability of live organisms of E. coli

Antisera prepared in pigs against living organisms of nine different strains of E. coli, five that produced both LT and ST in vitro and four that produced ST only, were each tested to determine whether they neutralised the ability 
H. WILLIAMS SMITH AND C. L. GYLES

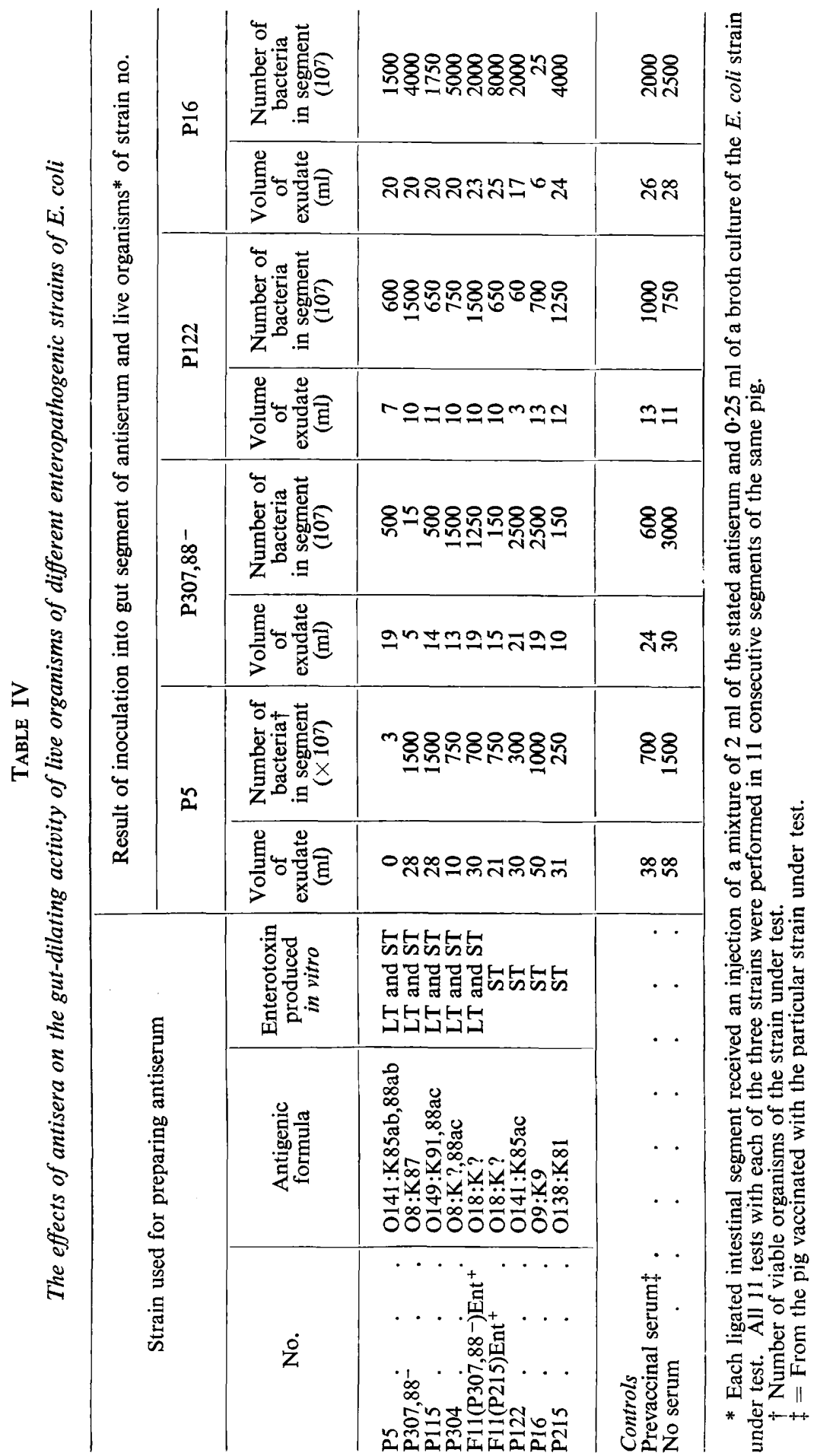


of the homologous strain or the other strains to dilate ligated intestinal segments. The interpretation of the results as a whole was complicated by the presence of natural bactericidal antibody against some of the strains in the serum of a few of the pigs used for preparing the antisera. The results of the tests with antisera against two strains producing LT and ST and against two strains producing ST only, all of which appeared to be uncomplicated by natural antibody, are summarised in table IV. These, and the results obtained with the other antisera, demonstrated that the antisera had a definite dilatationinhibiting effect, but that this effect was due to bactericidal antibody induced by vaccination and not to antitoxic antibody. Antiserum against strain F11(P307,88 $\left.{ }^{-}\right)$Ent + markedly inhibited the dilating effect of F11(P307,88 $\left.{ }^{-}\right)$Ent ${ }^{+}$ itself and of F11(P215)Ent ${ }^{+}$, but it had no effect against strains P307,88- and P215; very small numbers of live organisms of the former two strains and very large numbers of live organisms of the latter two strains were found in the segments in which they had been tested.

Further evidence that antitoxic antibody had little or no effect on the dilating ability of living organisms that produced both LT and ST was obtained in tests performed similarly to these described above, but with antisera that had been heated at $58^{\circ} \mathrm{C}$ for $1 \mathrm{hr}$. This procedure would not destroy LT antibody, but would inactivate the complement and hence the bactericidal activity of the antiserum. In these tests, strain P4(P307,88-)Ent + was tested against $\mathrm{F} 11\left(\mathrm{P} 307,88^{-}\right)$Ent ${ }^{+}$antiserum and $\mathrm{F} 11$ antiserum in pairs of segments in four pigs. The volumes $(\mathrm{ml})$ of fluid that accumulated in each pair of segments, that for the segment containing F11(P307,88 $\left.{ }^{-}\right)$Ent + antiserum being quoted first, were 49 and 40, 35 and 43, 33 and 13,20 and 18,19 and 11, 17 and 24, 14 and 16,13 and 12,12 and 14,12 and 13,11 and 17,8 and 9,7 and 6,6 and 11 , 6 and 6,5 and 9,5 and 8,5 and 8 , and 5 and 8 .

In a few agglutination tests that were performed, agglutinins could easily be demonstrated in the exudate that accumulated in segments that received mixtures of antisera and live cultures.

\section{The oral administration of LT and ST preparations to piglets}

The results of comparing the effect of the oral administration of LT-type and ST-type preparations to piglets from strains of $E$. coli that differed from each other only by virtue of the fact that some had received Ent during transmission experiments and others had not are summarised in table V. Both LT- and ST-type preparations of the Ent + strains produced diarrhoea whereas none of the piglets given Ent - preparations in similar dosage showed any sign of ill-health except two of 14 given $20 \mathrm{ml}$ of an LT-type preparation of F11(P307,88-)Ent ${ }^{-}$. In these two piglets, mild diarrhoea lasted 1-2 hr; otherwise, they appeared normal. By contrast, the diarrhoea produced in the piglets given LT and ST preparations of Ent + strains was severe. It lasted for 7-24 hr and was accompanied by pronounced clinical signs of dehydration; despite treatment, several of the piglets died. The diarrhoea commenced 3-5 hr after administration of the LT preparations and $2 \mathrm{hr}$ after administration of the ST preparations. 


\section{DisCUSSION}

Despite the differences between the heat-stable enterotoxin (ST) and the heat-labile enterotoxin (LT), the findings in the present study suggest that they are essentially two forms of the same enterotoxin. The findings supporting this view are as follows. (i) All the 40 wild strains of E. coli examined belonging

TABLE V

The results of oral administration of enterotoxin preparations to piglets

\begin{tabular}{|c|c|c|c|c|c|}
\hline \multicolumn{3}{|c|}{ Enterotoxin preparation administered } & \multirow{2}{*}{ Dose $(\mathrm{ml})$} & \multirow{2}{*}{$\begin{array}{l}\text { Number of piglets } \\
\text { treated }\end{array}$} & \multirow{2}{*}{$\begin{array}{l}\text { Number of piglets } \\
\text { that developed } \\
\text { diarrhoea }\end{array}$} \\
\hline Type & E. coli source & & & & \\
\hline \multirow[t]{4}{*}{ LT } & $\begin{array}{l}\text { F11(P307,88-)Ent }{ }^{+} \\
\text {F11(P307,88-)Ent } \\
\quad \text { None }\end{array}$ & & $\begin{array}{l}20 \\
20 \\
0^{*}\end{array}$ & $\begin{array}{l}14 \\
14 \\
36\end{array}$ & $\begin{array}{r}12 \\
2 \\
0\end{array}$ \\
\hline & $\begin{array}{l}\text { F11(P307,88-) } \text { Ent }^{+} . \\
\text {F11(P307,88-) }{ }^{+} \text {Nont } \\
\text { None }\end{array}$ & : & $\begin{array}{r}10 \\
10 \\
0\end{array}$ & $\begin{array}{l}5 \\
5 \\
4\end{array}$ & $\begin{array}{l}0 \\
0 \\
0\end{array}$ \\
\hline & $\begin{array}{c}\mathrm{K} 12 \mathrm{~F}-\left(\mathrm{P} 307,88^{-}\right) \mathrm{Ent}^{+} \\
\mathrm{K} 12 \mathrm{~F}-\left(\mathrm{P} 307,88^{-}\right) \mathrm{Ent}^{-} \\
\text {None }\end{array}$ & : & $\begin{array}{r}40 \\
40 \\
0\end{array}$ & $\begin{array}{l}4 \\
4 \\
4\end{array}$ & $\begin{array}{l}4 \\
0 \\
0\end{array}$ \\
\hline & $\begin{array}{c}\mathrm{K} 12 \mathrm{~F}^{-}-\left(\mathrm{P} 307,88^{-}\right) \mathrm{Ent}^{+} \\
\mathrm{K} 12 \mathrm{~F}-\left(\mathrm{P} 307,88^{-}\right) \mathrm{Ent}^{-} \\
\text {None }\end{array}$ & : & $\begin{array}{r}20 \\
20 \\
0\end{array}$ & $\begin{array}{l}5 \\
3 \\
4\end{array}$ & $\begin{array}{l}0 \\
0 \\
0\end{array}$ \\
\hline \multirow[t]{3}{*}{ ST } & $\begin{array}{l}\text { P104(P155)Ent }{ }^{+} \\
\text {P104(P155)Ent- } \\
\text { None }\end{array}$ & : & $\begin{array}{r}40 \\
40 \\
0\end{array}$ & $\begin{array}{l}8 \\
8 \\
8\end{array}$ & $\begin{array}{l}8 \\
0 \\
0\end{array}$ \\
\hline & $\begin{array}{l}\text { P104(P155)Ent }{ }^{+} \\
\text {P104(P155)Ent } \\
\text { None . }\end{array}$ & : & $\begin{array}{r}20 \\
20 \\
0\end{array}$ & $\begin{array}{l}4 \\
4 \\
4\end{array}$ & $\begin{array}{l}4 \\
0 \\
0\end{array}$ \\
\hline & $\begin{array}{l}\text { P104(P212)Ent }{ }^{+} \\
\text {P104(P212)Ent } \\
\text { None }\end{array}$ & $\dot{.}$ & $\begin{array}{r}20 \\
20 \\
0\end{array}$ & $\begin{array}{l}4 \\
4 \\
4\end{array}$ & $\begin{array}{l}4 \\
0 \\
0\end{array}$ \\
\hline
\end{tabular}

* Untreated controls.

to the principal serotypes that cause diarrhoea in pigs produced ST; none of them produced LT only. (ii) Production of both LT and ST was transmissible. Every LT-ST strain that was shown to transmit enterotoxin transmitted both characters together. It was not possible to obtain recipient organisms that produced only LT or only ST from mixed mating cultures in which these LT-ST strains were used as donors; they all produced both LT and ST. (iii) Antisera against living organisms of strains that had been shown to produce only ST neutralised LT. That a larger volume of such antisera than of antisera against LT-ST organisms was required to achieve neutralisation supports a view that strains classed as producers of ST alone also produce LT, but in 
amounts too small to be detected by the method we used. (iv) The lesion produced in ligated segments by LT was identical macroscopically with that produced by ST irrespective of the region of the small intestine in which tests were performed. An additive effect, too, was noted when LT and ST were injected together. (v) LT and ST produced the same clinical syndrome when given to piglets by mouth.

It is probable then that the plasmid, Ent, controlling enterotoxin production is basically the same in strains that produced both LT and ST and in the strains in which only ST production was detected; the differences in the composition of the enterotoxin of cultures of these two types of strains are perhaps due to minor differences in the Ent plasmid. Support for the existence of minor differences in Ent was obtained, for example, from the observation that P104 organisms that had received Ent from strain P155 were much better producers of enterotoxin than were P104 organisms that had received Ent from other strains. It is possible that ST is the actual substance that dilates ligated segments and produces diarrhoea, and that LT consists of ST, or a closely related substance, linked to protein, this linkage accounting for the heat susceptibility of LT, its antigenicity and its precipitability by ammonium sulphate (Gyles and Barnum, 1969).

The observation of Smith and Halls (1967b) that ST can sometimes be demonstrated in lysed cells of soft agar cultures of enteropathogenic strains was confirmed in the present study, but it was quite clear that its location was principally extracellular. Similarly the observation of Gyles and Barnum that LT can be demonstrated extracellularly in cultures in liquid media was confirmed, but it was not demonstrated with the same degree of constancy as it was in lysed cell preparations; this indicates that its location was principally intracellular. In view of these facts, it is conceivable that during enterotoxin synthesis LT is first formed and later " dissociates" to give the protein-free ST, the dissociation occurring more rapidly and more completely in cultures of the strains classed as producers of ST only than in cultures of the strains classed as producers of both LT and ST.

The reason for the close connexion between possession of K88 antigen and ability to produce detectable amounts of LT as well as ST remains a mystery. Although both characteristics are plasmid-controlled, there was no evidence of any functional relation between the two plasmids. The K88 plasmid was removed from and transmitted to strains without affecting the ST and LT content of the enterotoxin they produced. Similarly, none of the strains to which Ent of the LT-ST type was transmitted acquired the ability to produce K88 antigen. The answer probably lies buried in the evolutionary history of the porcine enteropathogenic strains. Loss of the K88 plasmid can occur relatively easily in some laboratory strains of $E$. coli. This may give rise to the

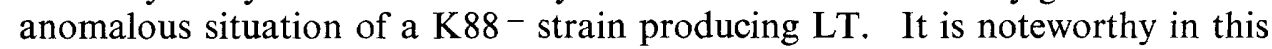
respect that Gyles and Barnum studied one strain-whose laboratory history was unknown-that had the antigenic formula $\mathrm{O} 141: \mathrm{K} 85 \mathrm{ab} \leftrightarrow \mathrm{ac}$ and yet consistently produced detectable amounts of LT.

Considered alone, the ease of neutralisation of LT by antiserum and the 
immunological similarity of the LT produced by antigenically different strains were encouraging from the viewpoint of the prevention of $E$. coli diarrhoea in the pig. However, the porcine enteropathogens also produce ST which was not neutralised by any of the different kinds of antiserum examined; the strains classed as "ST-only producers" dilated ligated segments to approximately the same extent as those classed as "LT-ST producers". Moreover, it was discouraging that the addition of antiserum to this latter type of strain did not affect the size of the dilatation produced, provided that it had no bactericidal effect against the organisms themselves. Bactericidal antibody was effective in preventing dilatation of ligated intestinal segments but, unfortunately, this effect was largely strain-specific.

The results of the oral administration of ST to piglets are in agreement with the findings of Kohler (1968); in addition we have shown that diarrhoea can also be caused by LT. The use in these experiments of materials prepared from strains that differed from each other solely by the presence or absence of the Ent plasmid strengthened the evidence that enterotoxin itself, and not other bacterial products, was the principal cause of the diarrhoea produced in the piglets. The fact that an LT-type preparation of the Ent- form of F11(P307,88-) did produce mild diarrhoea in two of 14 piglets indicated that some of these other products were, in fact, diarrhoea-producing. It also emphasised the value in this type of work of having available strains that differ solely by the presence or absence of a plasmid controlling the character under study.

Smith and Halls (1968) failed to produce diarrhoea in piglets with ST prepared from E. coli $\mathrm{P} 104(\mathrm{P} 3) \mathrm{Ent}^{+}$, the only strain they tested. The reason for the failure was probably inadequate concentration of ST in the preparation administered; in the present study, P104(P3)Ent ${ }^{+}$was shown to be a poorer producer of enterotoxin as judged by ligated intestine tests than were the two strains that yielded ST preparations that caused diarrhoea.

\section{SUMMARY}

Two enterotoxins formed by enteropathogenic strains of Escherichia coli of pig origin were studied. One of them (LT) was heat-labile and antigenic and the other (ST) was heat-stable and apparently non-antigenic. They were identified by their ability to dilate ligated segments of pig intestine.

The ST component was produced by all of 40 enteropathogenic pig strains examined and the LT component was produced only by those strains that naturally possessed, or had possessed, K88 antigen.

Both enterotoxins were found to be controlled by transmissible plasmids (Ent). In transmission experiments with donor strains that produced both LT and ST, it was not possible to isolate recipient strains that produced only one or other of these two enterotoxins; they all produced both. As a group, strains that had received Ent $\left(\mathrm{Ent}^{+}\right)$from donor strains that produced only ST dilated ligated segments to the same extent as did similar strains that had received Ent from donor strains that produced both ST and LT. 
The dilating effect of LT was neutralised by antisera prepared against live organisms of strains that produced LT and ST and, when larger doses were used, by antisera prepared against strains that had been shown to produce ST only. None of the antisera examined neutralised ST.

Antisera prepared against living organisms neutralised the dilating effect of these organisms. This neutralising effect was bactericidal, not antitoxic, in character and it appeared to be largely strain-specific.

ST and LT preparations of Ent + strains produced a similar type of severe diarrhoea when given by mouth to piglets. Similar preparations of the corresponding Ent - strains did not.

It is concluded that LT and ST are probably two forms of essentially the same enterotoxin.

We are grateful to Miss Diane Poulton, Miss Carole Smith and Miss Marion White for their capable technical help, and to Mr L. J. Abbott, Mrs Esther Johnson, Miss Margaret Linggood, Dr Ida Ørskov, Dr K. C. Sellers and Mr W. J. Sojka for help and assistance in a variety of ways. The expenses of this work were kindly defrayed by a grant from the Agricultural Research Council.

\section{REFERENCES}

Gyles, C. L., and Barnum, D. A. $\quad$ 1969. J. Infect. Dis., 120, 419.

KoHLER, E. M. . . . . . 1968. Amer.J. Vet. Res., 29, 2263.

Miles, A. A., Misra, S. S., and Irwin, 1938. J. Hyg., Camb., 38, 732. J. $O$.

Smith, H. W., and Halls, Sheila. 1967a. J. Path. Bact., 93, 499.

$\begin{array}{lll}\text { STIRM, S., ØRSKOV, IDA, AND ØRSKOV, F. } & \text { 1966. } & \text { Nature, Lond., 209, } 507 .\end{array}$ 